\title{
Role of Alpha Lipoic Acid on Metabolic Hepatosteatosis: An Experimental, Biochemical, and Microscopic Study
} Awatief A. Edries ${ }^{1,2}$, Ahmed H. El-Rashedy ${ }^{1,3}$, Mohamed Wagih ${ }^{4}$, M.H.Wahdan ${ }^{1,5}$

${ }^{1}$ College of Medicine, Taif, Saudi Arabia, ${ }^{2}$ Department of Tropical Medicine, Tanta University, Tanta, Egypt, ${ }^{3}$ Department of Pathology, College of Medicine, Al-Azhar University, Assuit, Egypt ,

${ }^{4}$ Department of Pathology, College of Medicine, Beni- Suef University, Beni-Suef Egypt,

${ }^{5}$ Department of Anatomy, College of Medicine, Cairo University, Egypt

*Corresponding author: dr.a_edrees@hotmail.com

\begin{abstract}
Background and aim of work: metabolic hepatosteatosis is a common serious prevalent condition in KSA. The current study investigated alpha lipoic acid (ALA) effects on hepatic lipid accumulation in severely fatty rats and secondarily on blood lipid profile.

Materials and methods: sixty male Zucker rats were selectively used half of which (Lean) weighed $200 \pm 25 \mathrm{~g} \&$ others weighed $375 \pm 30 \mathrm{~g}$. Fatty animals were allowed free access to food and water for one week before experiment. The animals were divided into lean untreated (group I), lean ALA managed (group II), fatty untreated (group III) and fatty ALA - managed (group IV) (fifteen animals per each group). ALA was taken orally ( $20 \mathrm{mg} / \mathrm{kg} /$ day) for six months. Animals were sacrificed and weighed (BW). Their liver was weighed (LW) and its portion was sliced to study its lipid content. Right tibia length (TL) was measured and LW: TL ratio was calculated.

Results: ZF ALA-untreated rats showed high LW: TL ratio. ALA therapy significantly reduced BW, TL, LW and LW: TL ratio in managed ZF rats compared to untreated ones while it didn't affect these parameters significantly in lean (ZL) rats. ZF rats exhibited significant hepatosteatosis evidenced by excessive liver triglyceride (TG) and total cholesterol (TC) contents and microscopically by large cytoplasmic vacuoles. Interestingly, 6-months' ALA therapy in ZF caused significantly diminished serum triglycerides and cholesterol levels as well as diminished hepatic triglycerides and TC component in addition to decreased its lipid vacuoles compared to untreated ZF rats. The results were insignificantly changed between managed and untreated lean groups.
\end{abstract}

Conclusion: our findings support effectiveness of ALA therapy in excessive hepatosteatosis and in hyperlipidemia via improving abnormal lipid metabolism.

Key words: Alpha lipoic acid- Fatty liver - Abnormal fat metabolism- Serum Chemistry Histopathology.

\section{INTRODUCTION}

Non-alcoholic fatty liver disease (NAFLD) represented a spectrum of disease ranging from hepatocellular steatosis through steatohepatitis to fibrosis and irreversible cirrhosis. ${ }^{(\mathbf{1})}$ Also, it was considered as part of the metabolic syndrome affecting adults and children and commonly associated with visceral adiposity, dyslipidaemia, hyperglycaemia and hypertension. Its importance was delivered from its high prevalence of up to $31 \%$ in the general worldwide population. $^{(3)}$ Metabolic hepatosteatosis was clinically important disorder in Saudi Arabia with estimated prevalence of $7 \%$ to $10 \% .{ }^{(4)}$ Hepatic steatosis was also commonly seen in patients with chronic hepatitis $\mathrm{C}$ virus (HCV) infection and had an increased prevalence in women with polycystic ovary syndrome when it was

usually associated with inflammatory reaction. ${ }^{(5)}$ Initial theories for the pathogenesis of NASH were based on 2-hit hypothesis; the first hit was hepatic triglyceride accumulation or steatosis that increased the susceptibility of liver to injury mediated by second hit exemplified by inflammatory cytokines/adipokines, mitochondrial dysfunction and oxidative stress which in turn could lead to steatohepatitis and/or fibrosis. ${ }^{(6)}$

However, free fatty acids (FFA) had been evidenced to play in directly progressing liver injury and could directly cause toxicity by increasing oxidative stress and by activation of inflammatory pathways. ${ }^{(7)}$ An increasing clinical and experimental evidences showed a greater 
production of oxygen free radicals (OFR) that could result in the known complications of non-alcoholic fatty liver. ${ }^{(8,9)}$

The potential therapeutic goal in management of hyperglycemia as well as obese with hepatosteatosis had related to achieve reduction in formation and activating power of these OFR. ${ }^{(10,}{ }^{11)}$ Exogenous antioxidant intake decreased the amount and functions of OFR; therefore, providing antioxidative effect in the liver cells. ${ }^{(12)}$

Alpha lipoic acid had an antioxidation character and was being a natural component that served as significant metabolic cofactor. It could essentially reduce many OFR. ${ }^{(13)}$ Furthermore, it removed the metallic ions and reformed a variety of certain antioxidants such as glutathione, ascorbic acid and tocopherol. ${ }^{(14,15)}$ Alpha lipoic acid, as well, had a powerful oxidative protecting renal and hepatic potential against cellular damage mediated by OFR. ${ }^{(16)}$ In addition, alpha lipoic acid application has been reported to be an improving therapeutic agent regarding endogenous insulin sensitivity ${ }^{(17,18)}$, therefore, preventing the incidence of hyperglycemic complications. ${ }^{(19)}$ The oxidative stress, defined by the disturbance between defensive antioxidant ability and formation of OFR, had been supposed to be concerned with the pathoetiology of many disorders including the cellular and subcellular membranous fat peroxidation that resulted in an intensive membranous destruction affecting its structure and therefore its function. ${ }^{(20)}$ Thus, cellular lipids peroxidation might cause cellular damage seen with several stress oxidant-mediated conditions. $^{(21)}$

It was advised to use large amounts of food antioxidants to overcome these stress associating oxidant-mediated disorders and thus removing and avoiding the harmful effects of OFR. ${ }^{(22)}$ Lipoic acid added to antioxidant-rich foods could be absorbed and traversed the blood brain barrier. Moreover, lipoic acid (LA) could act as a helping factor for several mitochondrial multi-enzyme complexes used for energy production.

Our work investigates the amelioration actions of lipoic acid on rat hepatosteatosis since obesity-mediated fatty liver could lead to serious worse effects and represented a considerable prevalence rate in Saudi Arabia.
In addition, it provides a safe protective therapy for this health problem that may affect the personal performance and reflect on the entire world economy.

\section{MATERIALS AND METHODS \\ Grouping of Animals and Therapeutic Administration}

Albino male rats used in this study were brought from animal house, Jeddah, KSA. Half of them selectively weighed $200 \pm 25$ (Lean) \& others weighed $375 \pm 30 \mathrm{~g}$ (Fatty). The rats were resided in a standard laboratory conditions for seven days at room temperature, in 50-60\% moistness and for twelve hours in light and similar hours in darkness. The animals received clean water as well as standard feeding. One week before starting this work, we allowed fatty animals for free feeding (on diet rich in animal fats and omega-6/omega-9-containing plant oils to induce hepatosteatosis) and drinking water. The used planning coincided with that of Biomedical Research in United States National Institute of Health Guidelines for Care. ${ }^{(24)}$

Four groups of rats were studied each of which involved fifteen animals; lean untreated group (Group I; LC) received distilled water $(0.5 \mathrm{ml})$, ALA managed lean group (II; LA), fatty untreated group (III; FC) received distilled water $(0.5 \mathrm{ml})$ and ALA managed fatty group (IV; FA). Daily administration of distilled water or ALA was performed through an oral cannula for duration of six months. Alpha lipoic acid (ALA) was taken orally in a dose of 20 $\mathrm{mg} / \mathrm{kg} /$ day dissolved in distilled water.

The triglycerides (TG) and total cholesterol (TC) kits were bought commercially from Wako; Osaka, Japan while as alpha lipoic acid powder was bought from Sigma, China.

Experimental Design: Depending upon the body weight, both serum TG and TC were measured prior to and after ALA treatment before sacrificing animals at the end of this study. The body weight (BW) was assessed every two weeks throughout the experiment alongside with serum lipids and right tibia length (TL). The rats' cervical vertebrae were dislocated after administration halothane anesthesia and then, the animals were weighed at the end of this work before 
sacrificing. Then, liver was removed \& drained with iced saline. We used a filter paper to get rid of extra water found on the liver's outer surface and then the heaviness of liver (Hepatic Weight; HW) was measured. To analyze total cholesterol (TC) and triglycerides (TG) liver contents, a part of liver was sliced, frozen in nitrogenous fluid and kept in minus eighty ${ }^{\circ} \mathrm{C}$. Also, the ratio between each TL value and liver weight was evaluated. The hepatic lipid contents were detected; as mentioned previously every two weeks throughout the study, in the centrifugated superficial fluid after homogenization and extraction of lipids from the processed hepatic piece using isopropanol in a concentration of $1 \mathrm{ml}$ per 50 $\mathrm{mg} .{ }^{(25)}$

\section{Histopathological Preparation Technique}

Small liver tissue pieces were fixed in ten percent formaldehyde to preserve tissue in as natural state as possible and prevent postmortem autolysis and putrefaction, then, the tissue was processed to remove water from it (tissue dehydration), then, it was embedded in waxy paraffin to make solid tissue blocks that were sectioned by a microtome into tissue slices of $5 \mu \mathrm{m}$ thickness. Finally the sliced sections were put on glass slides, stained with ordinary hematoxylin (Hx.) and eosin (E.) stains, covered with glass covers using Canada balsam and examined by light microscopy for assessment of the cases.

Data Studying: The informative results were described in mean values \pm Standard deviation (SD). We used student ' $t$ ' test analysis to achieve significant differences between each two (lean and fatty) animal sets. The statistical probability value ( $\mathrm{P}$ value) less than 0.05 was considered significant. Also, we performed SPSS statistical version 18 software package for our finding values.

\section{RESULTS}

Untreated Zucker fatty rats displayed elevated serum total cholesterol and triglycerides' levels at the beginning of this study while the serum levels of lipids were within normal values in two groups of Zucker lean animals (Table 1). The Liver weight (LW; expressed in grams) at the end of the experiment $\left(24^{\text {th }}\right.$ week $)$ was significantly decreased $(\mathrm{p}<0.05)$ in group IV regarding group III animals while the change in group II was insignificant concerning group I rats. In addition, liver weight at the end of our research showed the following means \pm standard deviations in the studied four groups respectively; $19.5 \pm 1.11,20.5 \pm$ $0.93,38.5 \pm 1.21$ and $24 \pm 0.83$. The hepatic total cholesterol (TC) content (expressed in $\mathrm{mg} / \mathrm{gm}$ of liver tissue) at the end of the experiment $\left(24^{\text {th }}\right.$ week $)$ was significantly decreased $(p<0.05)$ in group IV in relation to group III animals while the decrease in group II was insignificant $(p>0.05)$ concerning group I rats. Also, hepatic total cholesterol at the end of our study showed the following means \pm standard deviations in the studied four groups respectively; $6.02 \pm 0.41,6.01 \pm$ $0.23,9.37 \pm 0.24$ and $5.92 \pm 0.38$. The hepatic total triglycerides (TG) content (expressed in $\mathrm{mg} / \mathrm{gm}$ of liver tissue at the end of the experiment $\left(24^{\text {th }}\right.$ week $)$ was significantly decreased $(\mathrm{P}<0.05)$ in group IV in relation to group III animals while the decrease in group II was insignificant $(p>0.05)$ with reference to group I rats. Furthermore, hepatic total triglycerides at the end of this work showed the following means \pm standard deviations in the studied four groups respectively; $2.06 \pm$ $0.14,2.04 \pm 0.44,4.45 \pm 0.38$ and $2.02 \pm 0.29$. Moreover, at the end of this experiment, alpha lipoic acid (ALA) - managed Zucker fatty rats showed an improvement or decrease in the serum total cholesterol (significant $\mathbf{P}$ value; $\mathbf{0 . 0 2}$ ) and triglycerides (highly significant $\mathbf{P}$ value; $\mathbf{0 . 0 0 0}$ ) than untreated Zucker fatty rats whose serum lipid values were still elevated (Table $1 \&$ Figs. 2 and 3). Zucker fatty (ZF) whether untreated (FC) or ALA-managed (FA) rats had shorter TL with a highly significant $P$ value (P value $=\mathbf{0 . 0 0 0}$ ) in group IV compared to group III, however, the animals' body weights (B.Ws.) were greater than the lean ones whether untreated (LC) or ALA-managed (LA) rats. Also, B.Ws. in group II showed insignificant $P$ value $(P$ value $=\mathbf{0 . 6 7 4})$ compared to those of group I but they showed a highly significant $P$ value $(\mathbf{P}=\mathbf{0 . 0 0 0})$ in group IV rats corresponding to those of group III (Table $2 \&$ Figs. 4 and 5). Moreover, fatty rats displayed liver enlargement evidenced by its higher weight in addition to greater liver weight: TL relationship. In another meaning, Table 2 finally displayed that ALA therapy didn't 
significantly alter either the body weight or tibial length of ZL animals while both parameters were significantly diminished in ZF animals. ZF animals demonstrated excessive hepatosteatosis evidenced quantitatively by excessively higher liver triglycerides as well as microscopically by intracellular fatty droplets that appeared as large vacuoles occupying hepatocytic cytoplasm and pushing their nuclei to the periphery against the cell membrane giving signet-ring appearance (Fig1). In addition, there was an increased hepatic TC content. Interestingly, $\mathrm{ZF}$ rats managed with ALA showed surprising and significant diminution in both liver triglycerides quantity as well as intracytoplasmic lipid vacuoles (Fig.1). Moreover, ALA management displayed trivial and insignificant results in lean animals (group II).

\section{DISCUSSION}

In our work, fatty animals (ZF) demonstrated shorter tibia length TL and greater body weights regarding the lean ones. Also, ZF animals displayed hepatomegaly evidenced by its higher weight and its greater hepatic weight: TL ratio. Alpha lipoic acid (ALA) therapy highly significantly reduced the body weight and tibial length as well as it diminished both hepatic weight and weight: $\mathrm{TL}$ ratio in $\mathrm{ZF}$ managed group compared to untreated ZF one. Moreover, ALA didn't significantly influence these mentioned variables in managed lean group corresponding to untreated ZL one. Fatty animals revealed marked hepatosteatosis indicated by higher amounts of total hepatic triglycerides and total hepatic cholesterol together with intracytoplasmic fatty droplets visualized by light microscopy. Six-months ALA therapy of fatty animals significantly diminished quantities of total triglycerides and total cholesterol of fatty livers and improved intracytoplasmic fatty vacuoles of the hepatocytes. ALA management demonstrated trivial and insignificant influences on these parameters between lean animal groups. Significant improvement $(\mathrm{P}<0.05)$ of serum TC and highly significant diminution in serum $\mathrm{TG}$ had been encountered in ALA-managed $\mathrm{ZF}$ rats compared to untreated $\mathrm{ZF}$ animals. The serum lipids (TC \&TG) of ZL untreated animals were within normal values.
Furthermore, ALA managed ZL rats didn't show a significant decrease regarding untreated ZL ones. Our results, that were consistent with those of Morakinyo et al. ${ }^{(26)}$, explained the antioxidant activity of alpha lipoic acid which may be through multiple mechanisms including blockage of the cellular and subcellular lipid peroxidation, activation of the hepatic expressed genes related to oxidation of fatty acids and expression of antioxidant enzymes with subsequent decreased expression of sterol regulatory element binding protein-1 and acetyl COA carboxylase as well as subsequent increased expression of glucose transporter-4. Several researches performed on animals with insulin-resistance revealed a significant lowered hepatic triglycerides' component as well as fatness by peroxisome proliferator activated-alpha (PPAR $-\alpha)$ gene agonists (27). This gene's agonist had normalized obese hepatosteatosis (28) and severely enhances alcoholic hepatosteatosis as well as rats' hepatic triglycerides overloading. ${ }^{(29)}$ Moreover, fenofibrate, as an agonist for PPAR- $\alpha$ gene, intensely diminished hepatic triglyceride content that was associated with lowered plasma triglyceride level. ${ }^{(30)}$ Moreover, Morakinyo et al. ${ }^{(26)}$ and Akpinar et al. ${ }^{(31)}$, discovered lowering of the accumulated cardiac TG together with a decrease in the highly expressed certain messenger ribonucleic acids such as PPAR- $\alpha$ and acyl CoA oxidase (ACO) by hearts of diabetic fatty rats

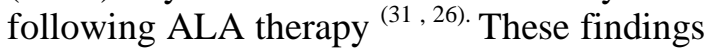
may be caused by the hypolipidemic effect of ALA that had been displayed in our group IV animals. Furthermore, Akpinar et al. ${ }^{(31)}$ explained an improvement of mRNA expression of certain genes including the PPAR- $\alpha$ and ACO ones by ZF rats' livers with ALA treatment. ${ }^{(32)}$ So, these results may suggest that ALA gave better quality for hepatosteatosis in ZF rats through activation of hepatic expressed genes related to oxidation of fatty acids.

The hepatic accumulation of fatty acids has been related to their uptake and synthesis as well as triglycerides' degradation. PPAR- $\gamma$ may activate the hepatic expression of gene included in fatty acids uptake and storage together with their synthesis. ${ }^{(32)}$ In contrast, there was a lowered hepatic expression of PPAR- $\gamma$ factor. ${ }^{(33)}$ 
Another factor termed SREBP-1 played a significant role in hepatic fat synthesis via activation of genes associated with hepatic lipogenesis. Alpha lipoic acid and gallic acid were found to increase the PPAR- $\gamma$ protein and mRNA expression in human mature phagocytes. ${ }^{(34)}$ On contrary, Morakinyo et $a l .^{(26)}$ displayed insignificant change in hepatic PPAR- $\gamma$-mediated expression of genes. ${ }^{(16)}$ They also found that SREBP- 1 mRNAs didn't vary in fatty rats relatively to the lean ones. Therefore, it has not been evidenced that ALA affected the expression of genes mediating the uptake and formation of fatty acids and also mediating the breakdown of triglycerides.

Interestingly, Shay et al. ${ }^{(35)}$ agreed our findings when they reported that ALA administration significantly lowered the weight of ZF livers, although they found that this substance had insignificant effect on the weight of ZL livers. ${ }^{(35)}$ They, as well, discovered potential antioxidant activity of ALA and its hepatoprotective character. In addition, Shaw et al. (36), emphasized hepatoprotective antioxidant and antiinflammatory effects of ALA in acute liver injury induced by chemicals as well as in chronic hepatic fibrosis and cirrhosis. ${ }^{(35,36)}$

This work concluded that ALA improved obese hepatosteatosis and secondarily serum lipid profile particularly and significantly in the obese rats. Therefore, this work was potentially considerable in providing our data in several clinical trials to elicit a protective safe drug used in the prevention and/or treatment of obesityassociated hepatosteatosis via changing of an unusual fat metabolic state.

\section{RECOMMENDATION}

Several future researches will be needed to clarify ALA working mechanism regarding its metabolic effects and to detect the relation of its antioxidant and antiinflammatory properties with diminution of the fatty livers' weight.

\section{REFERENCES}

1. Charlton M (2004): Nonalcoholic fatty liver disease: a review of current understanding and future impact. Clinical gastroenterology and hepatology: the official clinical practice. Journal of American Gastroenterological Association; 2:1048-1058.
2. Lazo M \& Clark JM (2008): The epidemiology of nonalcoholic fatty liver disease: a global perspective. Seminars in Liver Disease; 28:339350.

3. Brunt EM (2004): Nonalcoholic steatohepatitis. Seminars in Liver Disease; 24: 3-20.

4. Al-hamoudi W, El-Sabbah M, Ali S et al. (2012): Epidemiological, clinical, and biochemical characteristics of Saudi patients with nonalcoholic fatty liver disease: a hospital-based study. Annals of Saudi Medicine; 32: 288-292.

5. Hwang SJ \& Lee SD (2011): Hepatic steatosis and hepatitis C: Still unhappy bedfellows? Journal of Gastroenterology And Hepatology; 26: 96-101.

6. Day CP (2006): From fat to inflammation. Gastroenterology; 130: 207-210.

7. Feldstein AE, Werneburg NW, Canbay A et al. (2004): Free fatty acids promote hepatic lipotoxicity by stimulating TNF-alpha expression via a lysosomal pathway. Hepatology; 40: 185194.

8. Bashan N, Kovsan J, Kachko I, Ovadia H \& Rudich A (2009): Positive and negative regulation of insulin signaling by reactive oxygen and nitrogen species. Physiological Reviews; 89: 27-71.

9. Robertson RP (2004): Chronic oxidative stress as a central mechanism for glucose toxicity in pancreatic islet beta cells in diabetes. Journal of Biological Chemistry; 279: 42351-42354.

10. Campion J, Milagro FI, Fernandez D \& Martinez JA (2006): Diferential gene expression and adiposity reduction induced by ascorbic acid supplementation in a cafeteria model of obesity. Journal of Physiology And Biochemistry; 62: 7180.

11. Venditti P, Bari A, Di Stefano L \& Di Meo S (2007): Vitamin $\mathrm{E}$ attenuates cold-induced rat liver oxidative damage reducing $\mathrm{H} 2 \mathrm{O} 2$ mitochondrial release. International Journal of Biochemistry And Cell Biology; 39: 1731-1742.

12. Ihara Y, Toyokuni S, Uchida K, Odaka H, Tanaka T, Ikeda H, Hiai H, Seino Y \& Yamada Y (1999): Hyperglycemia causes oxidative stress in pancreatic beta-cells of GK rats, a model of type 2 diabetes. Diabetes; 48: 927-932.

13. Trujillo M \& Radi R (2002): Peroxynitrite reaction with the reduced and the oxidized forms of lipoic acid: new insights into the reaction of peroxynitrite with thiols. Archives of Biochemistry And Biophysics; 397: 91-98.

14. Bast A \& Haenen GR (2003): Lipoic acid: a multifunctional antioxidant. BioFactors; 17: $207-$ 213.

15. Petersen Shay K, Moreau RF, Smith EJ \& Hagen TM (2008): Is $\alpha$-lipoic acid a scavenger of reactive oxygen species in vivo? Evidence for its initiation of stress signaling pathways that 
promote endogenous antioxidant capacity. IUBMB Life; 60: 362-367.

16. Morakinyo A, Oludarego AA \& Adegoke O (2012): Protective effects of alpha lipoic acid on carbon tetrachloride-induced liver and kidney damage in rats. British Journal of Pharmacology And Toxicology; 3: 21-28.

17. Evans JL, Goldfine ID, Maddux BA \& Grodsky GM (2002): Oxidative stress and stress-activated signaling pathways: a unifying hypothesis of type 2 diabetes. Endocrine Reviews; 23: 599-622.

18. Kamenova $P$ (2006): Improvement of insulin sensitivity in patients with type 2 diabetes mellitus after oral administration of alpha-lipoic acid. Hormones; 5: 251-258.

19. Chang JW, Lee EK, Kim TH, Min WK, Chun S, Lee KU, Kim SB \& Park JS (2007): Effects of alpha-lipoic acid on the plasma levels of asymmetric dimethylarginine in diabetic endstage renal disease patients on hemodialysis: a pilot study. American Journal of Nephrology; 27: 70-74.

20. Matsumoto K, Yobimoto K, Huong NT, AbdelFattah M, Van Hien T \& Watanabe H (1999): Psychological stress-induced enhancement of brain lipid peroxidation via nitric oxide systems and its modulation by anxiolytic and anxiogenic drugs in mice. Brain Research; 839: 74-84.

21. Olivenza R, Moro MA, Lizasoain I, Lorenzo P, Fernández AP, Rodrigo J, Boscá L \& Leza JC (2000): Chronic stress induces the expression of inducible nitric oxide synthase in rat brain cortex. Journal of Neurochemistry; 74: 785-791.

22. Zaidi SKR \& Banu N (2004): Antioxidant potential of vitamins $\mathrm{A}, \mathrm{E}$ and $\mathrm{C}$ in modulating oxidative stress in rat brain. Clinica Chimica Acta; 340: 229-233.

23. Morikawa T, Yasuno R \& Wada H (2001): Do mammalian cells synthesize lipoic acid?: Identification of a mouse cDNA encoding a lipoic acid synthase located in mitochondria.The nucleotide sequence data of the mLIP1 cDNA for lipoic acid synthase of the mouse were deposited in the DDBJ, EMBL and GenBank nucleotide sequence databases with the accession number AB057731. FEBS Letters; 498: 16-21.

24. NIH (1985): Guide for the care and use of laboratory animals:US Department of Health.Human Services; NIH Publication.

25. Li Y, Qi Y, Kim MS, Xu KZ, Huang TH, Rong X, Murray M \& Yamahara J (2008): Increased renal collagen cross-linking and lipid accumulation in nephropathy of Zucker diabetic fatty rats. Diabetes/Metabolism Research And Reviews; 24: 498-506.

26. Morakinyo AO, Awobajo FO \& Adegoke OA (2013): Effects of alpha lipoic acid on blood lipids, renal indices, antioxidant enzymes, insulin and glucose level in streptozotocin-diabetic rats. Biology And Medicine; 5: 435-439.

27. Guerre-Millo M, Gervois $\mathbf{P}$, Raspe $\mathbf{E}$ et al. (2000): Peroxisome proliferator-activated receptor alpha activators improve insulin sensitivity and reduce adiposity. Journal of Biological Chemistry; 275: 16638-16642.

28. Ye JM, Iglesias MA, Watson DG, et al. (2003): $\mathrm{PPAR} \alpha / \gamma$ ragaglitazar eliminates fatty liver and enhances insulin action in fat-fed rats in the absence of hepatomegaly. American Journal of Physiology-Endocrinology And Metabolism; 284: 531-540.

29. Fischer M, You M, Matsumoto M \& Crabb DW (2003): Peroxisome proliferator-activated receptor alpha (PPARalpha) agonist treatment reverses PPARalpha dysfunction and abnormalities in hepatic lipid metabolism in ethanol-fed mice. Journal of Biological Chemistry; 278; 27997-28004.

30. Lee GY, Kim NH, Zhao ZS, Cha BS \& Kim YS (2004): Peroxisomal-proliferator-activated receptor alpha activates transcription of the rat hepatic malonyl-CoA decarboxylase gene: a key regulation of malonyl-CoA level. Biochemical Journal; 378: 983-990.

31. Akpinar D, Yargicoglu P, Derin N, Aliciguzel Y \& Agar A (2008): The effect of lipoic acid on antioxidant status and lipid peroxidation in rats exposed to chronic restraint stress. Physiological Research/Academia Scientiarum Bohemoslovaca; 57: 893-901.

32. Loviscach M, Rehman N, Carter $\mathbf{L}$ et al. (2000): Distribution of peroxisome proliferatoractivated receptors (PPARs) in human skeletal muscle and adipose tissue: relation to insulin action. Diabetologia; 43: 304-311.

33. Chou CJ, Haluzik M, Gregory C, Dietz KR, Vinson C, Gavrilova $O$ \& Reitman ML (2002): WY14, 643, a peroxisome proliferatoractivated receptor $\alpha$ (PPAR $\alpha)$ agonist, improves hepatic and muscle steatosis and reverses insulin resistance in lipoatrophic A-ZIP/F-1 mice. Journal of Biological Chemistry; 277: 2448424489.

34. Horton JD, Goldstein JL \& Brown MS (2002): SREBPs: activators of the complete program of cholesterol and fatty acid synthesis in the liver. Journal of Clinical Investigation; 109; 1125-1131.

35. Shay KP, Moreau RF, Smith EJ, Smith AR \& Hagen TM (2009): Alpha-lipoic acid as a dietary supplement: molecular mechanisms and therapeutic potential. Biochimica et Biophysica Acta (BBA)-General Subjects; 1790: 1149-1160.

36. Shaw JE, Sicree RA \& Zimmet PZ (2010): Global estimates of the prevalence of diabetes for 2010 and 2030. Diabetes Research And Clinical Practice; 87:4-14. 


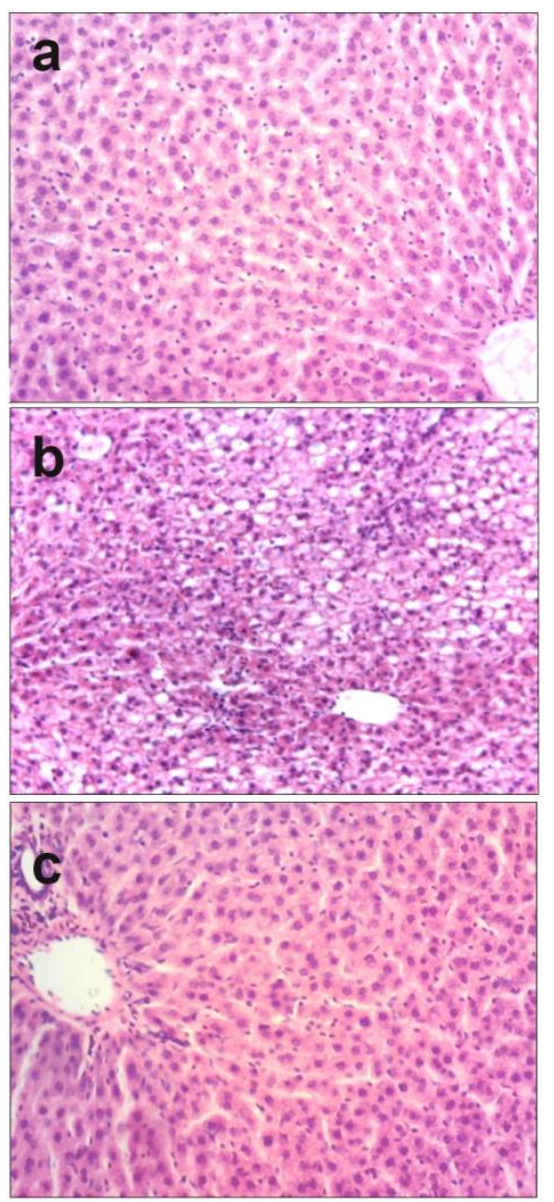

Figure 1: Hepatic tissue photomicrographs; (a) ZL (group I) photomicrograph showed no intrahepatocytic

fatty accumulation, (b) ZF (group III) photomicrograph displayed a signet ring appearance denoting intracellular fatty vacuoles deposition, and (c) ALA-managed ZF (group IV) photomicrograph revealed an absence of intrahepatocytic fatty deposition (Hx.\& E. original magnification power x100).

Table 1: Changes of serum total cholesterol (TC) \& triglycerides (TG) values among all studied lean and fatty groups:

\begin{tabular}{|c|c|c|c|c|c|c|c|c|}
\hline \multirow[b]{2}{*}{ Timing } & \multicolumn{4}{|c|}{ Serum TC (mmol/l) } & \multicolumn{4}{|c|}{ Serum TG $(\mathrm{mmol} / \mathrm{l})$} \\
\hline & $\begin{array}{c}\text { Lean } \\
\text { untreated } \\
\text { Group } \\
(\mathbf{n}=15)\end{array}$ & $\begin{array}{c}\text { Lean } \\
\text { ALA } \\
\text { managed } \\
\text { group } \\
(n=15)\end{array}$ & $\begin{array}{c}\text { Fatty } \\
\text { untreated } \\
\text { Group } \\
(\mathbf{n}=15)\end{array}$ & $\begin{array}{c}\text { Fatty } \\
\text { ALA } \\
\text { managed } \\
\text { group } \\
(n=15)\end{array}$ & $\begin{array}{c}\text { Lean } \\
\text { untreated } \\
\text { Group } \\
(\mathbf{n}=15)\end{array}$ & $\begin{array}{c}\text { Lean } \\
\text { ALA } \\
\text { managed } \\
\text { group } \\
(n=15)\end{array}$ & $\begin{array}{c}\text { Fatty } \\
\text { untreated } \\
\text { Group } \\
(\mathbf{n}=15)\end{array}$ & $\begin{array}{c}\text { Fatty } \\
\text { ALA } \\
\text { managed } \\
\text { group } \\
(n=15)\end{array}$ \\
\hline Day 0 & 4.76 & 4.77 & 5.12 & 5.10 & 0.94 & 0.96 & 1.67 & 1.62 \\
\hline Week 2 & 4.62 & 4.60 & 5.68 & $\mathbf{5 , 4 5}$ & 0.81 & 0.87 & 1.78 & 1.69 \\
\hline Week 4 & 4.65 & 4.63 & 5.79 & 5.74 & 1.07 & 1.05 & 1.93 & 1.88 \\
\hline Week 6 & 4.61 & 4.60 & 5.87 & 5.82 & 1.10 & 1.09 & 1.98 & 1.79 \\
\hline Week 8 & 4.67 & 4.65 & 5.99 & 5.89 & 0.95 & 0.93 & 2.09 & 1.86 \\
\hline Week 10 & 4.51 & 4.52 & 5.97 & 5.79 & 1.09 & 1.06 & 2.16 & 1.81 \\
\hline Week 12 & 4.33 & 4.42 & 6,13 & 6.09 & 1.05 & 1.01 & 2.19 & 1.79 \\
\hline Week 14 & 4.69 & 4.73 & 6.27 & 6.10 & 0.97 & 0.95 & 2.23 & 1.76 \\
\hline Week 16 & 4.73 & 4.71 & 6.29 & 6.24 & 0.91 & 0.88 & 2.28 & 1.85 \\
\hline Week 18 & 4.81 & 4.80 & 6.31 & 5.77 & 0.83 & 0.79 & 2.41 & 1.99 \\
\hline Week 20 & 4.64 & 4.61 & 6.36 & 5.52 & 1.05 & 1.03 & 2.54 & 2.02 \\
\hline Week 22 & 4.64 & 4.60 & 6.47 & 5.14 & 0.75 & 0.72 & 2.88 & 1.92 \\
\hline Week 24 & 4.55 & 4.54 & 6.68 & 4.79 & 0.69 & 0.65 & 2.32 & 1,56 \\
\hline $\begin{array}{c}\text { Mean } \pm \\
\text { SD }\end{array}$ & $4.63 \pm 0.12$ & $4.62 \pm 0.11$ & $6.07 \pm 0.40$ & $5.65 \pm 0.43$ & $0.94 \pm 0.14$ & $0.92 \pm 0.14$ & $2.19 \pm 0.32$ & $1.81 \pm 0.13$ \\
\hline$t$ test & \multicolumn{2}{|c|}{0.242} & \multicolumn{2}{|c|}{2.588} & \multicolumn{2}{|c|}{2.171} & \multicolumn{2}{|c|}{5.055} \\
\hline P value & \multicolumn{2}{|c|}{0.813 Non Sig. } & \multicolumn{2}{|c|}{ 0.02 Sig. } & \multicolumn{2}{|c|}{ 0.051 Non Sig. } & \multicolumn{2}{|c|}{ 0.000 H. Sig. } \\
\hline
\end{tabular}

This study was performed initially on 15 rats in each group; however, two in each group of animals were died during the experiment. 


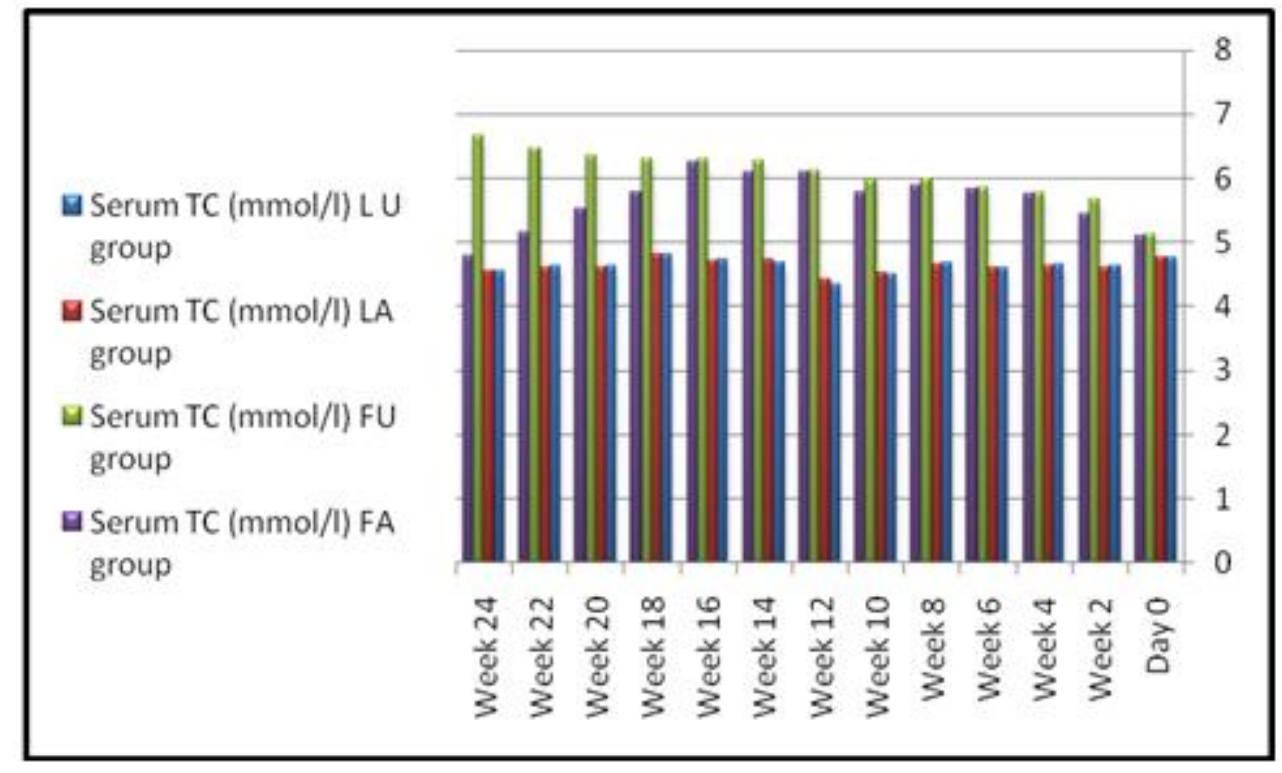

Figure 2: Chart representing mean values of serum total cholesterol (TC) in all studied groups throughout the study. LU=Lean untreated; LA= Lean alpha lipoic acid (ALA) managed; FU=Fatty untreated; FA=Fatty ALA-managed.

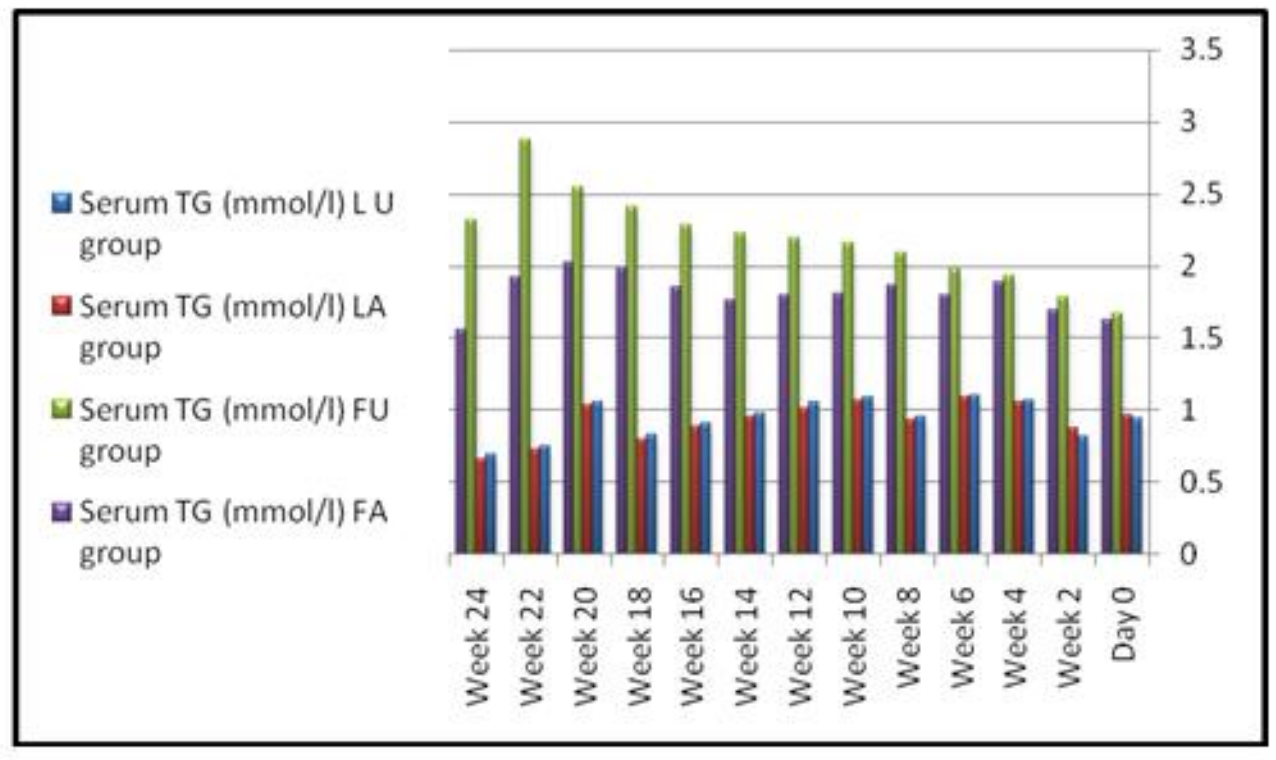

Figure 3:Chart representing mean values of serum total triglycerides (TG) in all studied groups throughout the study. $L U=L$ ean untreated; $L A=L$ Lean alpha lipoic acid (ALA) managed; FU=Fatty untreated; FA=Fatty ALA-managed. 
Table 2: Changes of body weight (BW) \& tibia length (TL) values among all studied lean and fatty groups:

\begin{tabular}{|c|c|c|c|c|c|c|c|c|}
\hline \multirow[b]{2}{*}{ Timing } & \multicolumn{4}{|c|}{ Body weight (gms) } & \multicolumn{4}{|c|}{ Tibia length (mm) } \\
\hline & $\begin{array}{c}\text { Lean } \\
\text { untreated } \\
\text { Group } \\
(\mathbf{n}=15)\end{array}$ & $\begin{array}{c}\text { Lean ALA } \\
\text { managed } \\
\text { group } \\
(n=15)\end{array}$ & $\begin{array}{c}\text { Fatty } \\
\text { untreated } \\
\text { Group } \\
(n=15)\end{array}$ & $\begin{array}{c}\text { Fatty } \\
\text { ALA } \\
\text { managed } \\
\text { group } \\
(\mathrm{n}=15) \\
\end{array}$ & $\begin{array}{c}\text { Lean } \\
\text { untreated } \\
\text { Group } \\
(n=15)\end{array}$ & $\begin{array}{c}\text { Lean } \\
\text { ALA } \\
\text { managed } \\
\text { group } \\
(\mathbf{n}=15) \\
\end{array}$ & $\begin{array}{c}\text { Fatty } \\
\text { untreated } \\
\text { Group } \\
(\mathbf{n}=\mathbf{1 5})\end{array}$ & $\begin{array}{c}\text { Fatty } \\
\text { ALA } \\
\text { managed } \\
\text { group } \\
(\mathbf{n}=15)\end{array}$ \\
\hline Day 0 & 188 & 190 & 353 & 357 & 21.00 & 23.00 & 19.3 & 19.2 \\
\hline $\begin{array}{c}\text { Week } \\
2\end{array}$ & 218 & 219 & 394 & 397 & 26.00 & 28.00 & 18.5 & 18.3 \\
\hline $\begin{array}{c}\text { Week } \\
4 \\
\end{array}$ & 211 & 213 & 399 & 363 & 26.00 & 25.00 & 18.3 & 18.2 \\
\hline $\begin{array}{c}\text { Week } \\
6 \\
\end{array}$ & 214 & 214 & 403 & 352 & 26.00 & 23.00 & 18.2 & 18.0 \\
\hline $\begin{array}{c}\text { Week } \\
8 \\
\end{array}$ & 215 & 216 & 411 & 345 & 27.00 & 28.00 & 18.2 & 18.0 \\
\hline $\begin{array}{c}\text { Week } \\
10 \\
\end{array}$ & 211 & 210 & 414 & 337 & 25.00 & 23.00 & 18.1 & 18.0 \\
\hline $\begin{array}{c}\text { Week } \\
12 \\
\end{array}$ & 217 & 218 & 417 & 321 & 28.00 & 26.00 & 18.1 & 17.8 \\
\hline $\begin{array}{c}\text { Week } \\
14 \\
\end{array}$ & 212 & 211 & 421 & 312 & 24.00 & 25.00 & 18.0 & 17.8 \\
\hline $\begin{array}{c}\text { Week } \\
16\end{array}$ & 218 & 217 & 424 & 310 & 28.00 & 29.00 & 18.0 & 17.7 \\
\hline $\begin{array}{c}\text { Week } \\
20 \\
\end{array}$ & 214 & 215 & 426 & 301 & 27.00 & 27.00 & 18.0 & 17.7 \\
\hline $\begin{array}{c}\text { Week } \\
22 \\
\end{array}$ & 222 & 221 & 431 & 293 & 28.50 & 26.00 & 17.9 & 17.6 \\
\hline $\begin{array}{c}\text { Week } \\
24 \\
\end{array}$ & 221 & 219 & 434 & 284 & 28.50 & 28.00 & 17.5 & 17.5 \\
\hline $\begin{array}{l}\text { Mean } \\
\pm \text { SD } \\
\end{array}$ & $\begin{array}{c}213.42 \pm 8 \\
.78 \\
\end{array}$ & $\begin{array}{c}213.58 \pm 8 \\
14 \\
\end{array}$ & $\begin{array}{c}410.58 \pm 2 \\
2.1 \\
\end{array}$ & $\begin{array}{c}331.0 \pm 33 \\
.3 \\
\end{array}$ & $\begin{array}{c}26.25 \pm 2 . \\
17 \\
\end{array}$ & $\begin{array}{c}25.92 \pm 2 . \\
15\end{array}$ & $\begin{array}{c}18.18 \pm 0 \\
43\end{array}$ & $\begin{array}{c}17.98 \pm 0 \\
45\end{array}$ \\
\hline t test & \multicolumn{2}{|c|}{0.432} & \multicolumn{2}{|c|}{5.326} & \multicolumn{2}{|c|}{0.655} & \multicolumn{2}{|c|}{6.665} \\
\hline P value & \multicolumn{2}{|c|}{ 0.674 Non Sig. } & \multicolumn{2}{|c|}{0.000 H. Sig. } & \multicolumn{2}{|c|}{ 0.526 Non Sig. } & \multicolumn{2}{|c|}{ 0.000 H. Sig. } \\
\hline
\end{tabular}

This study was performed initially on 15 rats in each group; however, three in each group of animals were died during the experiment. 


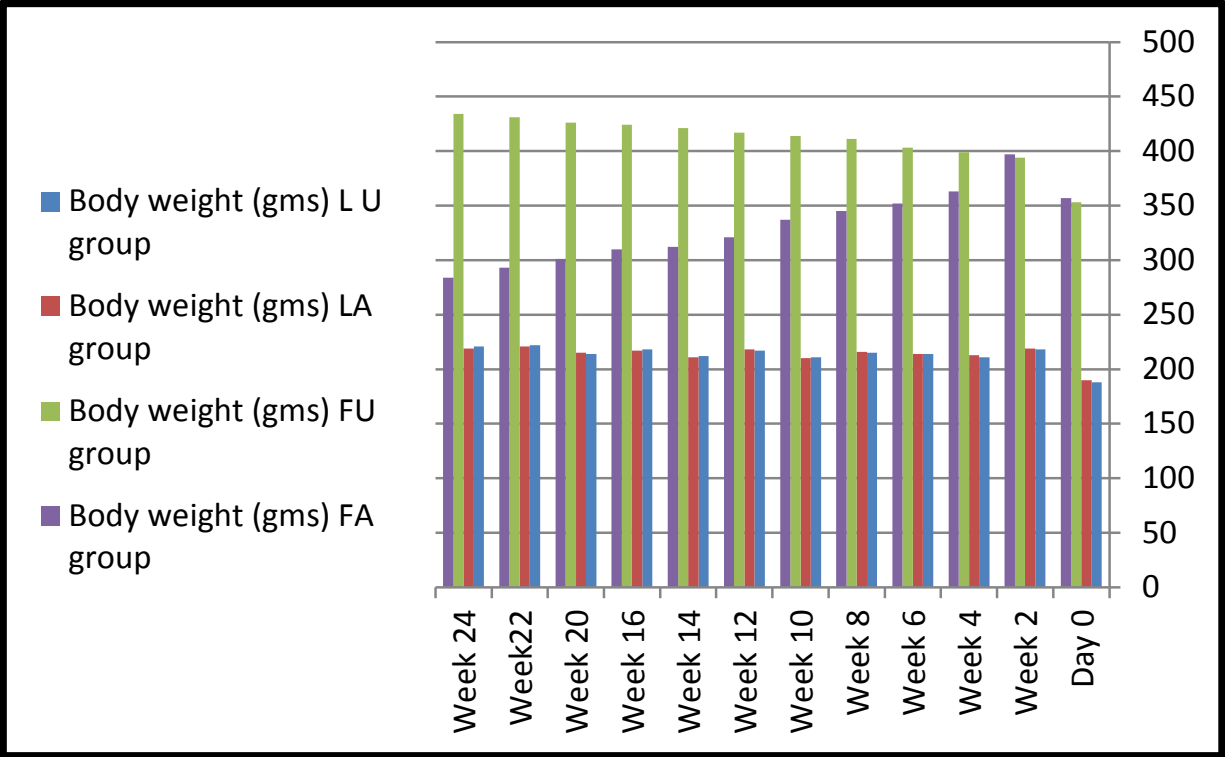

Figure 4:Chart representing mean values of body weight (BW) in all studied groups throughout the study. $L U=L e a n$ untreated; LA= Lean alpha lipoic acid (ALA) - managed; FU=Fatty untreated; FA=Fatty ALA-managed.

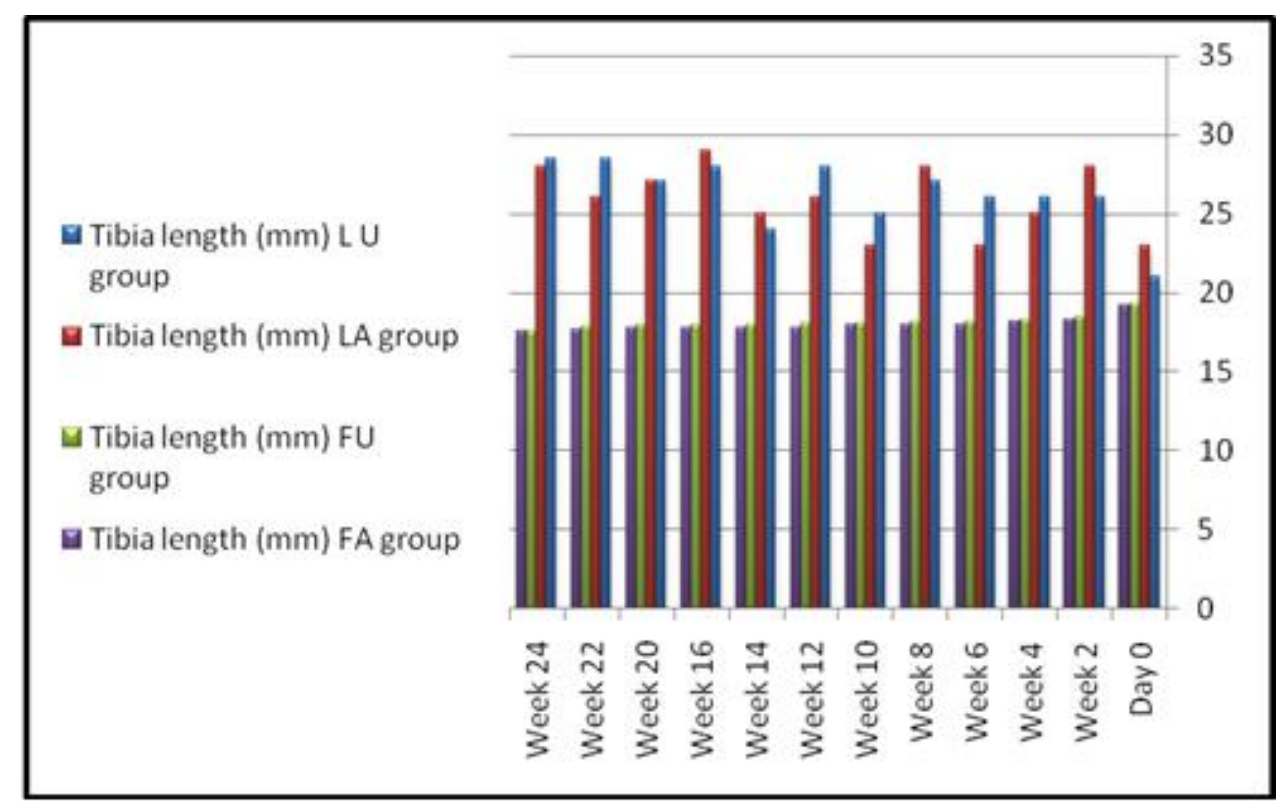

Figure 5:Chart representing mean values of tibia length (TL) in all studied groups throughout the study. $L U=L e a n$ untreated; $L A=$ Lean alpha lipoic acid (ALA) - managed; FU=Fatty untreated; FA=Fatty ALA-managed. 